\title{
ANALISIS HUBUNGAN SIMULTAN ANTARA KEPEMILIKAN MANAJERIAL, RISIKO, KEBIJAKAN HUTANG DAN KEBIJAKAN DIVIDEN DALAM MASALAH AGENSI
}

\author{
Nurfauziah \\ Fakultas Ekonomi Universitas Islam Indonesia \\ D. Agus Harjito \\ Fakultas Ekonomi Universitas Islam Indonesia \\ Atik Ringayati \\ Alumni Fakultas Ekonomi Universitas Islam Indonesia
}

\begin{abstract}
Abtract
In a company of go public is often happened the conflict between of stockholder with the manager, where manager act as the function of management and stockholder as function of is ownership. The conflict causes go together the importance difference between manager with the stockholder. Stockholder of course wish the manager work with an eye to maximize the stockholder prosperity. on the contrary, company manager might possibly act do not to maximize the stockholder prosperity but maximizing themselves prosperity. This research test the simultan relation between ownership of manajerial, risk, with the debt and dividen. Sample research as much 69 company, taken with the method of purposive sampling that is only company owning the ownership of incoming manajerial as sampel. To reach the wanted target, this research use the metode two stage least square. Result of research show the existence of consistent relation usher its variable that is negative relation among ownership of manajerial with the risk, debt. Positive relation between ownership of manajerial by dividen, negative relation among risk with the debt and dividen, and also negative relation among dividen with the debt.
\end{abstract}

Keywords: simultant relation, ownership of manajerial, risk, policy of debt and policy of dividend of agency problem

\section{PENDAHULUAN}

Tujuan utama perusahaan adalah untuk menaikkan nilai perusahaan dengan cara memaksimalkan kemakmuran pemegang saham. Karena itu diharapkan manajer yang diangkat oleh pemegang saham bertindak atas kepentingan pemegang saham. Hubungan keagenan terjadi ketika para pemegang saham (prinsipal) menyerahkan pembuatan keputusan finansial dan keputusan-keputusan yang lain kepada para manajer (agen). Pemegang saham tentu menginginkan manajer bekerja dengan tujuan memaksimumkan kemakmuran pemegang saham. Sebaliknya, manajer perusahaan bisa saja bertindak tidak untuk memaksimumkan kemakmuran pemegang saham tetapi memaksimumkan kemakmuran mereka sendiri. Penelitian ini bertujuan untuk mengetahui ada tidaknya hubungan secara simultan antara kepemilikan manajerial, risiko, kebijakan hutang dan kebijakkan dividen. Manfaat penelitian bagi kalangan investor, perusahaan serta pihak 
lain adalah dapat memberikan informasi mengenai hubungan interpendensi variabel kepemilikan manajerial, risiko, kebijakan hutang dan kebijakan dividen, digunakan untuk meminimumkan agency cost dengan mengetahui variabel mana yang dapat menimbulkan konflik agensi, digunakan sebagai bahan acuan untuk analisis mengenai teori keagenan selanjutnya.

\section{METODE PENELITIAN}

Tinjauan Literatur dan Pengajuan Hipotesis

Chen dan Steiner (1999) dalam penelitiannya " Manajerial ownership and Agency Conflict: A nonlinier Simultaneous Equation Analysis of Manajerial Ownership, Risk taking, Debt Policy, and Divuden Policy dengan metode analisis 2SLS. Hasil: 1) Manajerial ownership berhubungan dengan risiko secara non-linier, 2) Pengambilan risiko (risk taking) berhubungan positif dengan manajerial ownership, 3) Manajerial ownership mempunyai hubungan negatif dengan hutang dan dividen.

Jensen, et, al (1994) menguji pengaruh insider ownership, dividen terhadap hutang, penelitian ini menyatakan bahwa rasio debt merupakan fungsi dari insider ownership, dividend, business risk, profitability, R\&D dan Fixed Asset. Hasil penelitian yaitu terdapat hubungan negatif antara insider ownership dengan ratio debt, peningkatan kepemilikan manajerial menyebabkab penurunan rasio pembayaran dividen.

Wahidahwati (2002) menguji mengenai hubungan antara kepemilikan manajerial, risiko, hutang dan dividen. Hasilnya tidak terdapat hubungan non linier antara kepemilikan manajerial dengan risiko, hubungan antara manajerial ownership dan debt policy serta antara manajerial ownership dengan debt dan dividend policy mempunyai arah positif dan signifikan, hubungan antara manajerial ownership dengan divi- dend policy positif tidak signifikan, adanya pengaruh subtitutions-monitoring antara manajerial ownership dengan institutional ownership.

\section{Hubungan kepemilikan manajerial dengan} risiko

Demzetz dan Lehn (1985) menyatakan hubungan kausal negatif dari risiko terhadap kepemilikan manajerial. Treynor dan Black (1976), Amihud dan Lev (1981) dan Chen Steiner (1999)menemukan bukti empiris yang konsisten dengan hipotesis ini.

H1 : Ada hubungan negatif antara kepemilikan manajerial dengan risiko dalam mekanisme pengawasan masalah agensi.

\section{Hubungan kepemilikan manajerial dengan} dividen

Jensen (1986) yang mengargumenkan bahwa dividen mengurangi kos agensi yang terkait dengan free cash flows. Rozeff (1982), Chen dan Steiner (1999), juga telah menemukan hubungan kausal negatif dari dividen terhadap kepemilikan manajerial.

H2 : Ada hubungan negatif antara kepemilikan manajerial dengan dividen dalam mekanisme pengawasan masalah agensi.

\section{Hubungan kepemilikan manajerial dengan hutang}

Chen dan Steiner (1999), Tandelililn dan Wilberforce (2002) menemukan bahwa hutang memiliki hubungan negatif signifikan dengan kepemilikan manajerial. Friend dan Lang (1988) Jensen, Solberg dan Zorn (1992) Wahidahwati (2002) menyatakan bahwa perusahaan dengan managerial ownership besar mempunyai andil besar dalam mengurangi hutang. Jensen dan Meckling (1976), Leyland dan Pyle (1997) dan Kim dan Sorenson (1986) berpendapat bahwa hutang 
mengurangi kebutuhan ekuitas eksternal dan meningkatkan proporsi kepemilikan manajerial.

H3 : Ada hubungan negatif antara kepemilikan manajerial dengan hutang dalam mekanisme pengawasan masalah agensi.

\section{Hubungan risiko dengan dividen}

Jensen et.al (1992), Chen dan steiner (1999) menyatakan adanya hubungan negatif antara risiko dengan dividen. Kale dan Noe (1990), Venkatesh (1989) mengembangkan sebuah model dimana risiko yang lebih besar timbul sebagai akibat dari rendahnya pembayaran dividen.

H4 : Ada hubungan negatif antara risiko dengan dividen dalam mekanisme pengawasan masalah agensi.

\section{Hubungan risiko dengan hutang}

Ravid (1988) menyatakan adanya hubungan negatif antara risiko dengan hutang. Chen dan Steiner (2000), Jensen et al (1992), menyatakan bahwa hutang yang besar dalam struktur modal perusahaan akan memberikan risiko kebangkrutan yang tinggi.

H5 : Ada hubungan positif antara risiko dengan hutang dalam mekanisme pengawasan masalah agensi.

\section{Hubungan dividen dengan hutang}

Jensen (1986) berpendapat bahwa baik dividen maupun hutang dapat bekerja untuk mengendalikan biaya keagenan dari aliran dana bebas. Chen dan Steiner (1999) dan Jensen et al (1992) menyatakan bahwa pembayaran dividen muncul sebagai pengganti hutang didalam struktur modal.

H6 : Ada hubungan negatif antara dividen dengan hutang dalam mekanisme pengawasan masalah agensi.

\section{Pengukuran Variabel}

a. Kepemilikan Manajerial (IOWN). Diukur dari pembagian jumlah saham yang dimiliki oleh manajemen dengan jumlah saham beredar. Variabel ini diperoleh dari Indonesian Capital Market Directory (ICMD) tahun 20012004 pada bagian shareholder ownership. (Joher, Ali, dan Nazrul: 2005).

b. Risiko Bisnis (RISK), yang dihasilkan dengan menggunakan standar deviasi total return perbedaan pertama pendapatan operasi (operating income) selama empat tahun. (Jansen, Solberg dan Zorn : 1992).

c. Hutang (DEBT), yang diukur dengan membagi jumlah hutang dengan nilai buku total aset. Sumber data variabel ini adalah ICMD 2001-2004 pada bagian summary of financial statement. (Rajan dan Zingaels: 1995).

d. Dividen (DIV). Variabel ini merupakan rasio dari pembayaran dividen terhadap laba bersih setelah pajak (EAT).

e. Ukuran perusahaan (SIZE), dihitung dari perkalian antara jumlah saham yang beredar dengan harga saham akhir tahun. (Tandelilin \& Wilberforce: 2002).

f. Pertumbuhan Perusahaan (GROWTH), dihitung dari pertumbuhan penjualan selama empat tahun (2001-2004). (Tandelilin \& Wilberforce: 2002).

g. Profitabilitas (PROFIT), diukur dengan membagi pendapatan operasi dengan total aset (Jansen, Solberg dan Zorn: 1992), (Tandelilin \& Wilberforce: 2002).

h. Aset Tetap (FASET), diproxikan oleh rasio aset tetap terhadap aset total perusahaan (Tandelilin \& Wilberforce: 2002).

\section{Model Penelitian \\ Model empiris}




\section{$\mathrm{DIV}=\mathrm{d}_{19}+\mathrm{d}_{20} \mathrm{IOWN}+\mathrm{d}_{21} \mathrm{DEBT}+\mathrm{d}_{22} \mathrm{RISK}$ $+\mathrm{d}_{23} \mathrm{SIZE}+\mathrm{d}_{24}$ PROFITe}

\section{Sampel dan data penelitian}

Populasi dalam penelitian ini adalah perusahaan yang terdaftar di BEJ pada periode 2001-2004 karena pada saat itu keadaan perekonomian Indonesia cukup stabil dan tidak banyak terjadi gejolak ekonomi. Sampel diambil dengan metode purposive sampling yaitu mengambil anggota populasi dari saham yang tercatat di BEJ, sampel telah listed di BEJ sejak tahun 2001 atau sebelumnya, sampel memiliki data tentang insider ownership. Penelitian ini menggunakan data sekunder. Data diperoleh dari laporan keuangan tahunan perusahaan yang dimuat dalam Indonesian Capital Market Directory.

\section{Model pengujian hipotesis}

Model yang digunakan dalam penelitian ini untuk menguji signifikansi hubungan simultan kombinasi beberapa variabel bebas terhadap variabel tergantung. Dalam persamaan simultan variabel endogen dalam suatu persamaan akan muncul dalam persamaan lain dalam suatu sistem. Penelitian ini menggunakan empat model persamaan.

Penelitian ini menggunakan model persamaan Two Stage Least Square (2SLS). Pengujian dengan 2SLS karena ordinary least square tidak dapat menjelaskan hubungan timbal balik dalam sistem persamaan simultan.

\section{HASIL PENELITIAN}

Hasil Analisis 2SLS

\begin{tabular}{|c|c|c|c|c|}
\hline \multirow{2}{*}{$\begin{array}{c}\text { Variabel } \\
\text { Independen }\end{array}$} & \multicolumn{4}{|c|}{ Variabel Dependen } \\
\hline & IOWN & RISK & DEBT & DIV \\
\hline Konstanta & $\begin{array}{c}0.223603 \\
(0.0266)^{* *}\end{array}$ & $\begin{array}{r}0.0000656 \\
(0.7022)\end{array}$ & $\begin{array}{c}0.432599 \\
(0.0304)^{* *}\end{array}$ & $\begin{array}{c}-114.1083 \\
(0.0041)^{\star * *}\end{array}$ \\
\hline IOWN & & $\begin{array}{c}-0.051939 \\
(0.0010)^{\star * \star}\end{array}$ & $\begin{array}{r}-0.650029 \\
(0.7312)\end{array}$ & $\begin{array}{r}20.37326 \\
(0.6640)\end{array}$ \\
\hline DIV & $\begin{array}{r}0.000404 \\
(0.2169)\end{array}$ & $\begin{array}{r}-2.55 \mathrm{E}-05 \\
(0.5777)\end{array}$ & $\begin{array}{r}-0.005216 \\
(0.2098)\end{array}$ & \\
\hline DEBT & $\begin{array}{r}-0.003722 \\
(0.6357) \\
\end{array}$ & $\begin{array}{r}-0.000444 \\
(0.6854) \\
\end{array}$ & & $\begin{array}{r}-0.446547 \\
(0.8757) \\
\end{array}$ \\
\hline RISK & $\begin{array}{r}-1.207657 \\
(0.4590) \\
\end{array}$ & & $\begin{array}{r}-13.85840 \\
(0.3253)\end{array}$ & $\begin{array}{r}-29.24627 \\
(0.9304)\end{array}$ \\
\hline $\mathrm{RISK}^{2}$ & $\begin{array}{r}0.434302 \\
(0.2770)\end{array}$ & & & \\
\hline PROFIT & & $\begin{array}{r}0.016722 \\
(0.1832)\end{array}$ & & $\begin{array}{r}90.83801 \\
(0.0094)^{* * *}\end{array}$ \\
\hline GROWTH & & & $\begin{array}{c}0.405019 \\
(0.0234)^{\star *}\end{array}$ & \\
\hline FASET & & $\begin{array}{r}-0.000529 \\
(0.8848)\end{array}$ & $\begin{array}{r}0.491843 \\
(0.2403)\end{array}$ & \\
\hline SIZE & $\begin{array}{l}-0.007995 \\
(0.0453)^{* *}\end{array}$ & & & $\begin{array}{r}4.708998 \\
(0.0028)^{\star * *}\end{array}$ \\
\hline R-squared & 0.210126 & 0.173272 & 0.124038 & 0.433244 \\
\hline Adj R-squared & 0.147437 & 0.107659 & 0.124038 & 0.388264 \\
\hline
\end{tabular}

Signifikan pada level $0.1, * *$ Signifikan pada level , *** Signifikan pada level 0.01 


\section{Persamaan Kepemilikan Manajerial}

Penelitian ini menghasilkan hubungan negatif tidak signifikan. Arah negatif sesuai dengan penelitian Treynor dan Black (1976), Amihud dan Lev (1981), Demzetz dan Lehn (1985), Chen Steiner (1999). Dimungkinkan karena pada level risiko yang masih rendah, manajer di Indonesia sudah mempunyai sifat enggan terhadap risiko (risk averse). (RISK ${ }^{2}$ ) memiliki hubungan positif namun tidak signifikan dengan kepemilikan manajerial, menunjukan bahwa pada saat risiko naik manajer justru akan meningkatkan tingkat kepemilikannya di perusahaan dalam rangka untuk mengurangi risiko tersebut.

Hutang memiliki hubungan negatif dan tidak signifikan dengan kepemilikan manajerial. Arah negatif sesuai dengan penelitian Friend dan Lang (1988), Chen dan Steiner (1999), Tandelilin dan Wilberforce (2002). Dimungkinkan karena penggunaan hutang yang banyak meningkatkan risiko kebangkrutan yang pada akhirnya meningkatkan risiko yang tidak dapat terdiversifikasi bagi para manajer sehingga melemahkan kepemilikan manajerial

Dividen menunjukkan hubungan positif namun tidak signifikan dengan kepemilikan manajerial. Hasil positif tersebut sesuai dengan penelitian Wahidahwati (2002). Kemungkinan lain bahwa antara kepemilikan manajerial dan dividen tidak berlaku hubungan saling mengganti dalam peranan pengawasan agensi atau tidak ada hubungan substitution. Yang ada hubungan saling melengkapi (complementary). Selain itu, dengan adanya kepemilikan manajerial yang tinggi, maka manajer semakin mampu dalam melakukan atau mengatur dividen.

Ukuran perusahaan (SIZE) memiliki hubungan negatif dan signifikan dengan kepemilikan manajerial, sesuai dengan Chen dan steiner (1999), Jensen et al (1992), Bathala et al (1994). Kemungkinan bahwa perusahaan besar akan memberikan batasan bagi manajer, jika mereka memiliki kepemilikan saham yang besar. Nilai perusahaan yang semakin besar akan mereduksi kepemilikan manajerial sehingga berkurangnya kendali manajer terhadap perusahaan karena perusahaan dengan skala besar akan membatasi tindakan manajer.

\section{Persamaan Risiko}

Kepemilikan manajerial pada persamaan risiko mempunyai nilai koefisien negatif dan signifikan. Arah hubungan yang negatif dan signifikan tersebut sesuai dengan penelitian Wahidahwati (2002), Chen Steiner (1999), manajer lebih menyukai investasi kurang berisiko dan menggunakan hutang lebih rendah supaya dapat menurunkan risiko ketidakpastian investasi mereka dan mengurangi kemungkinan kebangkrutan perusahaan. Penjelasan lain yang mungkin adalah manajer yang risk averse melakukan diversifikasi secara optimal untuk mengurangi risiko pribadi. Pada saat kekayaan pribadi tidak terdiversifikasi, manajer menuntut insentif tinggi untuk mengimbangi risiko yang diterima.

Hutang pada persamaan risiko menunjukkan hubungan negatif dan tidak signifikan. Hasil ini sesuai dengan penelitian Ravid (1988). Koefisien negatif tersebut mengindikasikan bahwa risiko yang lebih tinggi diperkirakan mengurangi antusiasme perusahaan terhadap hutang. Kemungkinan dengan risiko yang tinggi perusahaan kurang mempertimbangkan lebih dalam untuk melakukan hutang.

Dividen menunjukkan hubungan negatif dan tidak signifikan dalam persamaan risiko. Arah hubungan yang negatif sesuai dengan Kale dan Noe (1990), Vankatesh (1989), Jensen et.al (1992), Chen dan steiner (1999). Kemungkinan bahwa perusahaan dengan risiko bisnis yang tinggi maka ketidakpastian pendapatan di masa datang juga semakin besar tetapi perusahaan 
kurang menghindari komitmen untuk membagikan dividen dalam jumlah yang besar di masa datang.

Koefisien profit pada persamaan risiko menghasilkan hubungan positif dan tidak signifikan. Hasil ini sesuai dengan Jensen et al (1992) dan Turiyasingura (2000) menyatakan bahwa perusahaan yang profitable akan mempunyai banyak dana yang tersedia untuk investasinya sehingga akan menurunkan penggunaan hutang yang dimungkinkan akan menaikkan risiko.

Hasil penelitian menunjukkan bahwa aset tetap memiliki hubungan negatif tidak signifikan dengan risiko. Arah negatif sesuai dengan Chen Steiner (1999). Kemungkinan bahwa aset tetap menunjukkan struktur aset suatu perusahaan, aset tetap yang tinggi merupakan kolateral sehingga perusahaan tersebut dipercaya oleh pemberi hutang (debtholders) dan dipandang sebagai perusahaan dengan risiko yang rendah untuk penanaman saham.

\section{Persamaan Hutang}

Hasil penelitian ini menunjukkan bahwa kepemilikan manajerial pada persamaan hutang memiliki koefisien yang negatif dan tidak signifikan. Arah hubungan yang negatif sesuai dengan free cash flow hyphotesis, Jensen (1986). Hasil ini dimungkinkan karena perusahaan dengan kepemilikan manajerial yang besar mempunyai andil yang besar dalam mengurangi risiko.

Risiko pada persamaan hutang memiliki negatif dan tidak signifikan. Hasil penelitian ini sesuai dengan penelitian yang dilakukan oleh Ravid (1988). Kemungkinan dengan adanya risiko yang tinggi menyebabkan perusahaan untuk mempertimbangkan lebih dalam untuk melakukan hutang. Apabila perusahaan melihat bahwasannya risiko akan hutang tersebut rendah, maka perusahaan akan meningkatkan hutang tersebut. Namun apabila risiko dari hutang tersebut tinggi, maka perusahaan akan mengurangi hutangnya.

Dividen menghasilkan nilai koefisien negatif dan tidak signifikan dalam persamaan hutang, meskipun tidak siginifikan tetapi arah hubungannya sesuai dengan temuan Jensen et.al (1992) bahwa perusahaan melakukan trade off antara pembayaran dividen dengan pembayaran hutang.

GROWTH pada persamaan hutang memiliki koefisien positif dan signifikan. Hasil ini bertentangan dengan Titman dan Wessels (1988), Myers dan Majluf (1984). Hasil penelitian dapat dimungkinkan pertumbuhan perusahaan yang besar membutuhkan modal atau sumber dana yang tinggi yang diperoleh dari hutang untuk membiayai investasi.

Hasil penelitian menunjukkan bahwa aset tetap memiliki hubungan negatif dan tidak signifikan dengan hutang. Arah hubungan negatif sesuai dengan penelitian Scott (1976), Chen Stainer (1999), Jensen et al (1992) dan Turiyasingura (2000). Sesuai dengan collateral hyphotesis yang menyatakan bahwa fix asset dapat digunakan sebagai jaminan untuk mengajukan hutang kepada kreditor.

\section{Persamaan Dividen}

Kepemilikan manajerial mempunyai hubungan positif namun tidak signifikan. Arah yang positif sesuai dengan penelitian Wahidahwati (2002). Hasil yang positif tersebut dimungkinkan karena kepemilikan manajer yang tinggi, maka kekayaannya semakin tidak terdiversifikasi dengan baik, oleh karena itu manajer akan mengharapkan return atas opportunity cost yang lebih besar yaitu dari pembagian dividen yang tinggi. Kemungkinan lain bahwa dengan adanya kepemilikan manajerial yang tinggi, manajer semakin mampu untuk mengatur pembagian dividen.

Hutang pada persamaan dividen memiliki koefisien negatif namun tidak sig- 
nifikan. Hasil ini sesuai dengan penelitian Jensen et.al (1992). Kemungkinan bahwa penggunaan hutang yang tinggi akan menyebabkan pembayaran beban tetap berupa kos bunga, sehingga akan menyebabkan penurunan laba dan kemudian akan menyebabkan tingkat rasio dividen yang rendah.

Risiko pada persamaan dividen memiliki koefisien negatif namun tidak signifikan. Hasil ini sesuai dengan penelitian Kale dan Noe (1990), Jensen et.al (1992), Chen dan steiner (1999). Perusahaan dengan risiko bisnis tinggi maka ketidakpastian pendapatan di masa datang juga semakin besar sehingga perusahaan menghindari komitmen untuk membagikan dividen dalam jumlah yang besar di masa datang.

Hasil dari persamaan dividen menunjukkan bahwa ukuran perusahaan (SIZE) memiliki hubungan negatif dan signifikan.Hasil ini sesuai dengan penelitian Wahidahwati (2002). Hal ini mengindikasikan bahwa semakin besar ukuran perusahaan (SIZE) semakin besar pula rasio dividen Hal tersebut terjadi karena per usahaan yang ukuran perusahaannya tinggi cenderung ingin melindungi pemegang saham dengan meningkatkan dividennya agar perusahaan tersebut selalu direspon positif, sehingga meningkatkan nilai perusahaan.

Profit memiliki hubungan positif dan signifikan, sesuai dengan Jensen et.al (1992). Semakin tinggi profitabilitas perusahaan, maka semakin tinggi pula cash flow dalam perusahaan, dan diharapkan perusahaan akan membayar dividen yang lebih tinggi.

\section{KESIMPULAN DAN SARAN}

Hubungan antara kepemilikan manajerial dengan risiko yang rendah adalah negatif namun tidak signifikan. Kemungkinan dikarenakan pada level risiko yang masih rendah, manajer bersifat risk averse. Penelitian ini juga menemukan adanya hubungan positif tetapi tidak signifikan antara kepemilikan manajerial dengan risiko yang naik, dimungkinkan karena manajer di Indonesia pada saat risiko naik justru meningkatkan porsi kepemilikan sahamnya dalam rangka mengurangi risiko yang naik. Hipotesis pertama yang menyatakan ada hubungan negatif antara kepemilikan manajerial dengan risiko dalam mekanisme pengawasan masalah agensi ditolak. Hasil penelitian menunjukkan adanya hubungan yang negatif namun tidak signifikan antara kepemilikan manajerial dengan dividen sehingga hipotesis kedua yang menyatakan bahwa antara keduanya mempunyai hubungan positif ditolak. Hal ini menunjukkan bahwa perusahaan di Indonesia antara kepemilikan manajerial dan dividen tidak berlaku hubungan saling mengganti dalam peranan pengawasan agensi. Yang ada hubungan saling melengkapi (complementary). Kemungkinan lain adanya kepemilikan manajerial yang meningkat, manajer tersebut mempunyai kemampuan untuk mengatur dividen. Hasil dari analisis hubungan antara kepemilikan manajerial dengan hutang menunjukkan hubungan yang negatif namun tidak signifikan sehingga hipotesis ketiga ditolak. Kemungkinan bahwa hutang yang tinggi akan menyebabkan risiko kebangkrutan, yang pada akhirnya meningkatkan risiko yang tidak terdiversifikasi bagi para manajer sehingga melemahkan kepemilikan manajerial. Hasil penelitian menunjukkan positif sehingga hipotesis keempat yang menyatakan ada hubungan negatif antara risiko dengan dividen dalam mekanisme pengawasan masalah agensi ditolak. Kemungkinan dari hasil tersebut bahwa perusahaan dengan risiko bisnis yang tinggi, ketidakpastian pendapatan di masa mendatang juga semakin besar sehingga perusahaan menghindari komitmen untuk membagikan dividen dalam jumlah besar di masa mendatang. Ketidaksignifikan menyebabkan hipotesis kelima yang menyatakan 
ada hubungan positif antara risiko dengan hutang dalam pengawasan masalah agensi ditolak. Kemungkinan bahwa risiko yang lebih tinggi diperkirakan mengurangi antusiasme perusahaan terhadap hutang. Selain itu dimungkinkan karena pertimbangan yang kurang dalam oleh perusahaan dalam melakukan hutang. Hasil penelitian menunjukkan adanya arah hubungan negatif namun tidak signifikan antara dividen dengan hutang sehingga hipotesis keenam ditolak. Kemungkinan bahwa antara keduanya dapat bekerja untuk mengendalikan biaya keagenan dari aliran dana bebas. Sebagai akibatnya, semakin besar pembayaran dividen maka semakin kecil kebutuhan hutang untuk mengontrol biaya keagenan.

Beberapa hasil dari penelitian ini menunujukkan ketidaksignifikanan mungkin disebabkan oleh data yang sedikit. Sampel yang kecil terjadi karena hanya perusahaan yang telah terdaftar sejak tahun 2001 dan sebelumnya serta memiliki struktur kepemilikan manajerial saja yang digunakan sebagai sampel dalam penelitian ini. Kemungkinan lain tidak efektifnya beberapa variabel pengurang masalah agensi untuk mengurangi masalah agensi di Indonesia. Di Indonesia masalah agensi memang tinggi, kemungkinan karena di Indonesia kepemilikannya lebih dominan pada kepemilikan terkonsentrasi pada keluarga, serta di Indonesia konflik kepentingan terjadi antara pemegang saham mayoritas dengan pemegang saham minoritas.

Hubungan negatif dan signifikan antara kepemilikan manajerial dengan ukuran perusahaan, kemungkinan bahwa perusahaan besar akan memberikan batasan bagi manajer, jika mereka memiliki kepemilikan saham yang besar. Profit dengan risiko memiliki hubungan positif tidak signifikan yang mengindikasikan bahwa perusahaan yang profitable akan mempunyai banyak dana yang tersedia untuk investasinya sehingga akan menurunkan penggunaan dana hutang yang dimungkinkan akan menaikkan risiko. Faset mempunyai hubungan negatif tidak signifikan dengan risiko, aset tetap yang tinggi merupakan kolateral sehingga perusahaan tersebut dipandang sebagai perusahaan dengan risiko yang rendah untuk penanaman saham. GROWTH dengan hutang memiliki hubungan positif dan signifikan menunjukkan pertumbuhan perusahaan yang besar membutuhkan modal atau sumber dana yang tinggi yang diperoleh dari hutang untuk membiayai investasi. Hubungan positif tidak signifikan antara aset tetap dengan hutang kemungkinan bahwa perusahaan dengan fix asset besar cenderung kurang menggunakan hutang yang besar. Ukuran perusahaan dengan dividen mempunyai hubungan positif dan signifikan kemungkinan bahwa perusahaan yang ukuran perusahaannya tinggi cenderung melindungi pemegang saham dengan meningkatkan dividennya agar perusahaan tersebut selalu direspon positif. Profit dengan dividen mempunyai hubungan yang positif dan signifikan menunjukkan bahwa semakin tinggi profitabilitas perusahaan, semakin tinggi pula cash flow dalam perusahaan, diharapkan perusahaan akan membayar dividen yang lebih tinggi.

Penelitian selanjutnya disarankan untuk lebih teliti dalam mengidentifikasikan dan menelusuri struktur kepemilikan pada sampel yang diteliti yaitu struktur kepemilikan mencakup direktur, manajer maupun anggota tim manajemen lain yang memegang saham perusahaan secara langsung serta menelusuri perusahaan yang dimiliki oleh para pemegang saham tersebut, lebih memperhatikan kembali kriteriakriteria sampel yang dibutuhkan agar lebih mampu menjelaskan karakteristik populasi yang diteliti dan lebih memperpanjang periode penelitian, lebih banyak mengkaji variabel kontrol yang digunakan agar lebih beragam dan hasilnya relevan. 


\section{DAFTAR PUSTAKA}

Amihud, Y. And B. Lev. (1981). "Risk Reduction as a Managerial Motive for Conglomerate Mergers." Journal of Economic, 12, 605-617.

Arifin, Z. (2003). "Efektifitas Mekanisme Bonding Deviden dan Hutang untuk Mengurang Masalah Agency." Jurnal Siasat Bisnis, Vol. 1, No. 8, 19-31. (2005). Teori Keuangan dan Pasar Modal. Edisi Pertama. Yogyakarta: Ekonisia.

Bathala, C. T, K. P. Moon, dan R. P. Rao. (1994). "Managerial Ownership, Debt Policy, and The Impact of Institutional Holding: an Agency Perspective." Financial Management, 23, 38-50.

Chen, C.H. dan Steiner. (1999). "Managerial Owenership and Agency Conflict a Nonlinier Simultaneous Equation Analysis of Managerial Ownership, Risk Taking, Debt Policy, and Deviden Policy.” The Financial Review, Vol. 34, 119-137.

Crutchley, C.E, M.R.H. Jensen, J.S. Jahera dan J.E. Raymond. (1999). "Agency Problem and The Simultaneity Decision Making The Role of Institusional Ownership." International Review of Financial Analysis, 8.

Friend, I and L.H.P Lang. (1988). "An Empirical Test of the Impact of Managerial SelfInterest on Corporate Capital Structure." The Journal of Finance, 43, 271-28.

Gujarati. D .(terjemahan). (1995). Ekonometrika Dasar. Erlangga. Jakarta.

Hanafi M. Mamduh. (2003). "Kepemilikan Manajerial, Kepemilikan Institutional, Risiko, Kebijakan Hutang dan Kebijakan Dividen: Analisis Persamaan Simultan", Simposium Nasional Akuntansi VI.

Jensen M. (1986). "Agency Cost of Free Cash Flow, Corporate Finance and Takeovers." American Economic Review, 76, 323-329.

Jensen M, and W Mecling. (1976). "Theory of The Firm: Managerial Behavior Agency, and Ownership Structure.” Journal of Financial Economics, 305-360.

Jensen, G.R, D.P. Solberg dan T.S Zorn, (1992), "Simultaneous Determination of Insider Ownership, Debt, and Dividend Policies." Journal of Financial and Quantitative Analysis, 247-263.

Joher H, Ali M, Nazrur, (2005), "The Impact of Ownership Structure On Corporate Debt Policy: Two Stage Least Square Simultaneous Model Approach.” Journal of Financial and Quantitative Analysis, 1-19.

Jogiyanto, Mahadwartha A. Putu, (2002), "Uji Teori dalam Hubungan Interdependensi Antara Kebijakan Hutang dengan Kebijakan Dividen”, Simposium Nasional Akuntansi V.

Kale, J.R and T.H Noe. (1990). "Dividend and Uncertainty and Underwriter Costs Under Asymmetric Information." Journal of Financial Research, 13, 265-277.

Kim, W.S and Sorenson. (1986). "Evidence on The Impact of Agency Cost of Debt on Corporate Debt Policy.” Journal of Financial and Quantitative Analysis, 21, 131-144. 
SIIERGI Vol. 9 No. 2, JUNI 2007: 157 - 166

Leland, H, and D. Pyle. (1977). "Informational Asymetries, Financial Structure, and Financial Intermediation." Journal of Finance, 32, 371-388.

Myers. S, and N.M Maljuf. (1984). "Corporate Financinf and Investment Decitions When Firms Have Information That Investors D Not Have." Journal of Finance, 39, 187221.

Ravid. S.A. (1988). "On Interaction of Production and Financial Decision." Financial Management, 17, 87-99.

Rozeff. M. (1982). "Growth, Beta and Agency Costs as Determinants of Dividend Payout Ratios." Journal of Financial Research, 3, 249-259.

Sartono, A. (2001). "Kepemilikan Orang Dalam (Insider Ownership), Utang dan Kebijakan Deviden: Pengujian Empirik Teori Keagenan (Agency Theory). Jurnal Siasat Bisnis, No. 6, Vol. 2,107-119.

Scott, J.H.Jr. (1976). "Theory of Optimal Capital Structure.” Bell Journal of Economics, 7, 33-53.

Tandelilin, E. dan Wilberforce, T. (2002). "Can Debt and Dividend Policies Substitute Insider Ownership in Controlling Equity Agency Conflict?."Gadjah Mada International Journal of Finance. Vol. 4. No. 1. 31-43.

Titman dan Wessels (1988) dalam Joher H, Ali M, Nazrur. (2005). "The Impact of Ownership Structure On Corporate Debt Policy : Two Stage Least Square Simultaneous Model Approach." Journal of Financial and Quantitative Analysis, 119.

Treynor J, and F Black. (1976). "Corporate Invesment Decisions, Modern Developments in Financial Management.” (Praeger New York), 310-327.

Turiyasingura. (2000). "Substitutability of Agency Conflict Control Mechanisms: A Simultaneous Equation Analysis of Insider Ownership, Debt and Dividend Policies."

Vankatesh. P. (1989). "The Impact of Dividend Initiation on The Information Content of Earning ennouncements and Return Volatility." Journal of Business, 62, 175-198.

Wahidahwati. (2002). "Kepemilikan Manajerial dan Agensi Konflik: Analisis Persamaan Simultan Non Linier dari Kepemilikan Manajerial, Penerimaan Risiko (Risk Taking), Kebijakan Hutang dan Kebijakan Dividen." Simposium Nasional Akuntansi V. 